\title{
APONTAMENTOS SOBRE A ADOÇÃO DAS BOAS PRÁTICAS DE GOVERNANÇA NAS ORGANIZAÇÕES DO TERCEIRO SETOR. IMPORTÂNCIA DA ADOÇÃO DE UM PROGRAMA DE COMPLIANCE EFETIVO, A LUZ DA LEI N. 12.846 /2015
}

Julia Maria Gracia de Castro ${ }^{1}$

\section{Resumo}

O presente trabalho busca apresentar e sugerir as práticas de boa governança aplicáveis às organizações do Terceiro Setor. Sem esgotar o tema, trata de apontar os benefícios da adoção de mecanismos de transparência e controle, internos e externos, de forma a permitir uma gestão mais profissionalizada de tais entidades, atenuando a assimetria informacional e minorando os problemas de agência, sempre na busca do desempenho social eficiente. $\mathrm{Na}$ sequência, uma breve análise das principais leis que regulamentam as organizações sem fins lucrativos destaca diversas exigências legais sob a ótica das boas práticas de governança. Por fim, sendo o compliance (ou conformidade legal) um dos pilares da boa governança, o texto evidencia a importância da adoção de um programa eficiente, à luz da Lei n. 12.846/2015 e do Decreto n. 8.420/2015.

Palavras-chave: Organizações do Terceiro Setor; práticas de boa governança; compliance; lei anticorrupção.

\section{CONSIDERAÇÕES INICIAIS}

O Terceiro Setor, resultado da mobilização e organização da sociedade civil em prol do atingimento de suas necessidades sociais, com a criação de entidades que buscam alargar as alternativas para o acesso a bens ou serviços de caráter social e/ou econômico, cresceu e tornou-se mais forte, haja vista a incapacidade do Estado em concentrar, com exclusividade, o desenvolvimento de ações de políticaspúblicas.

A evolução do setor é deveras impressionante. No Brasil, o estudo divulgado pelo IBGE sobre Fundações Privadas e Associações sem Fins Lucrativos no Brasil (Fasfil ${ }^{2}$ ), em dezembro de 2012, apontou a

\footnotetext{
${ }^{1}$ Advogada, Mestre em Direito Internacional pela Universidade do Estado do Rio de Janeiro - UERJ. E-mail: gracia.julia@gmail.com

${ }^{2}$ Segundo o IBGE, o "Fasfil constitui referência de dados e análises para o conhecimento da sociedade civil organizada no Brasil, não apenas porque traz um agrupamento das organizações por áreas de atuação e informa sobre seus empregados, como também porque revela como elas estão distribuídas no território brasileiro e qual sua perenidade”. As Fundações Privadas e Associações sem Fins Lucrativos no Brasil (2010) - FASFIL. Rio de Janeiro: IBGE, 2012. Disponível em <ftp://ftp.ibge.gov.br/Fundacoes_Privadas_e_Associacoes/2010/fasfil.pdf>, capturado em 15/01/2015. 
existência de 290,7 mil entidades. O Yearbook of International Organizations³ ${ }^{3}$ por sua vez, mapeou a existência de mais de 60 mil entidades internacionais, localizadas em 300 países e seusterritórios.

No atual estágio de desenvolvimento do setor, a importância das organizações sem fins lucrativos transborda o papel exercido na sociedade, diante do montante de recursos por elas administrados ${ }^{4}$. A título ilustrativo, pesquisa realizada pelo Programa de Voluntários da Nações Unidas aponta que as Organizações do Terceiro Setor (OTS) representam 5\% do Produto Interno Bruto do Brasil ${ }^{5}$. Segundo o Instituto de Pesquisa Econômica Aplicada (IPEA), o governo federal dispendeu quase R \$ 190 bilhões entre 2003 e 2011 em convênios com outros níveis de governo e com entidades sem fins lucrativos. Estas entidades (onde se inclui, além de Organizações Não Governamentais, sindicatos, hospitais filantrópicos, fundações e institutos de pesquisa, centros culturais, dentre outras) receberam perto de $15 \%$ do total de transferências, num valor de R $\$ 29$ bilhões em mais de 36 mil convênios 6 .

Ora, números tão expressivos não passam despercebidos na sociedade civil atual, que tem direcionado interesse crescente às entidades do Terceiro Setor, em especial por parte de seus financiadores, órgãos fiscalizadores e colaboradores, demandando maiores informações sobe a alocação dos recursos, bem como sobre os resultados apresentados.

\footnotetext{
3 "The Yearbook of International Organizations includes detailed information on over 37,000 active and 30,000 dormant international organizations from 300 countries and territories - including intergovernmental (IGOs) and international nongovernmental organizations (INGOs). Approximately 1,200 new organizations are added each year." Union of International $\begin{array}{lllllll}\text { Organizations. } & 51 \text { st } & \text { Print } & \text { Edition } 2014 & - & \text { Disponível em }\end{array}$ <http://www.uia.org/yearbook?width=500\&height=100\&inline=true\#faq-igo $>$, capturado em 20/04/2015.

${ }^{4}$ A título de exemplo, a United Nations Statistics Division (UNSTATS), em seu Handbook on Non-Profit Institutions in the System of National Accounts (2003), aponta ser cada vez mais importante se obter uma noção mais clara da abrangência das Organizaçōes Não Governamentais (tidas lato sensu), dentre outras razões: "NPIs [non-profit institution] constitute a significant and growing economic force in countries throughout the world. NPIs have recently come to be recognized as a major economic presence in countries throughout the world. Indeed, what one analyst has termed a "global associational revolution", a massive upsurge of organized private voluntary activity, seems to be under way in many parts of the world at the present time as a product of changes in communications, new popular pressures and growing questioning of the capabilities of government to solve pressing social and economic problems on its own. Indeed, recent research has demonstrated that non-profit organizations account for 8 to 12 per cent of non-agricultural employment in many developed countries and even larger shares of formal employment in many developing regions. Because much of the revenue supporting that sizeable non-profit sector comes from public sector payments in Western Europe and from fees and charges in Japan, the United States and Australia, however, that set of institutions is allocated to the government and corporate sectors, respectively, in SNA [System of National Accounts] and therefore largely disappears from view. The resources controlled by institutions identified as NPISHs [non-profit institutions serving households] in SNA thus turn out to represent only a small portion of all the resources controlled by non-profit institutions in most countries". Handbook on Non-Profit Institutions in the System of National Accounts. United Nations, New York, 2003, p. 03. Disponível em <http://unstats.un.org/unsd/publication/seriesf/seriesf_9le.pdfs, capturado em 16/02/2015.

5 "As instituiçōes sem fins lucrativos são responsáveis por 5\% do Produto Interno Bruto (PIB) do Brasil — uma participação superior à de setores expressivos da economia brasileira, como a indústria de extração mineral (petróleo, minério de ferro, gás natural, carvão, entre outros), e maior que a de 22 Estados brasileiros (só fica atrás de São Paulo, Rio de Janeiro, Minas Gerais, Rio Grande do Sul e Paraná)." Disponível em <http://www.pnud.org.br/Noticia.aspx?id=901>. Capturado em 16/04/2015.

${ }^{6}$ LOPEZ, Felix. BARONE. Leonardo. As Entidades Sem Fins Lucrativos e as Políticas Públicas Federais: tipologia e análise de convênios e organizações. (2003-2011). Texto para discussão n¹896. IPEA, Brasília, nov. 2013, p. 07.
} 
A bem da verdade, diversos escândalos envolvendo entidades não governamentais, que desviaram de suas finalidades as doações de pessoas físicas, jurídicas, ou mesmo verba oriunda de parcerias com o poder público, têm ditado, ainda que intuitivamente, a necessidade de imprimir a reformulação no setor, de forma a minimizar o abalo à credibilidade e o receio da má alocação dos recursos por elasgeridos.

Neste cenário, nota-se uma mudança na administração de ditas organizações, que se antes era marcada por certo amadorismo, hoje tende a incorporar técnicas mais modernas de gestão e controle, tendo por norte a transparência, a prestação de contas, a equidade e a conformidade legal. A transparência na prestação de contas, em especial, não é mais vista como uma obrigação fiscal apenas: é também uma obrigaçãosocial.

Vemos, assim, que os quatro pilares da boa governança não são desconhecidos das organizações, notadamente a implementação de uma política efetiva de compliance ${ }^{8}$, pois não se vislumbra a possibilidade de adotarem-se mecanismos eficientes de governança em sua ausência, de forma a fortalecerem-se os controles internos e mitigar-se os riscos de prejuízo à atividade, à reputação e de aplicação de sanções diversas.

\section{ADOÇÃO DAS BOAS PRÁTICAS DE GOVERNANÇA CORPORATIVA PELAS ORGANIZAÇÕES DO TERCEIRO SETOR NA BUSCA DO DESEMPENHO SOCIAL EFICIENTE.}

Recente reportagem ${ }^{9}$ apresentada do Observatório da Sociedade Civil, em parceria com a Associação Brasileira das Organizações Brasileiras Não Governamentais (ABONG), apresenta interessante panorama das origens dos recursos das entidades do Terceiro Setor, concluindo que a marca de tal financiamento no Brasil é a diversidade de fontes. Ou seja, uma grande parcela das OTS não recebe da Administração Pública, ou, ao menos, com exclusividade, os recursos necessários para a consecução de seu fim social.

Grande parte de tais recursos advém de doações (pessoas físicas ou jurídicas) e, em muitos casos, sua força de trabalho é composta por voluntários, que não são os destinatários do fim social das OTS. Assim, a questão da confiança dos financiadores (quanto à boa utilização dos recursos) é essencial para a continuidade da entidade.

\footnotetext{
${ }^{7}$ Cabe observar que, muito embora as entidades do Terceiro Setor não distribuam resultados financeiros, existe relação de agência entre os gestores da organização (agentes) e seus doadores e voluntários (principais).

${ }^{8}$ Pode-se definir compliance, ou conformidade legal, como "Adoção pelas corporações de um código de ética para seus principais executivos, que deverá conter formas de encaminhamento de questões relacionadas a conflitos de interesse, divulgação de informações e cumprimento de leis e regulamentos", muito embora, ao nosso ver, não deva ser limitada aos gestores ou principais executivos, devendo abranger os funcionários e colaboradores. ROSSETTI, José Paschoal. ANDRADE, Adriana. Governança corporativa: fundamentos, desenvolvimento e tendências. 5a ed. atual. e ampl. São Paulo: Atlas, 201 1, p. 178.

${ }^{9} \mathrm{O}$ dinheiro das ONGs: Como as Organizações da Sociedade Civil sustentam suas atividades - e porque isso é fundamental para o Brasil. Disponível em: http://www.revistaforum.com.br/blog/2014/02/de-onde-vem-o-dinheiro-das-ongs/. Acessado em 21/01/2015.
} 
As organizações sem fins lucrativos enfrentam até hoje os seguintes desafios ${ }^{10}:$ o da legitimidade, que diz respeito à formalização legal e transparência/divulgação de suas ações e resultados; o da eficiência, quanto à profissionalização da instituição; o da sustentabilidade, seja financeira ou humana; e o da colaboração com o poder público, o setor empresarial e as demais OTS, que desempenham o papel de competidoras dos recursos disponíveis.

Na superação de tais desafios, como abordado nas linhas introdutórias, faz-se necessária a adoção de práticas eficientes de governança, com o engajamento de todos os setores da entidade, desde a alta gestão, até os executores das atividades sociais (funcionários, colaboradores) desempenhadas pela entidade, o que irá propiciar seu fortalecimento, bem como reduzir a desconfiança que a sociedade tem em relação ao seu desempenho. A Lei 12.846/2013 (doravante chamada "Lei Anticorrupção") veio a reforçar tal necessidade, ao levar em consideração a "existência de mecanismos e procedimentos internos de integridade, auditoria e incentivo à denúncia de irregularidades e a aplicação efetiva de códigos de ética e de conduta no âmbito da pessoa jurídica" (art. $7^{\circ}$, VIII) na aplicação das sanções.

Isto porque, nas palavras de Joaquim Fontes Filho:

"Qualquer organização, seja ela privada pública ou do terceiro setor, tem em sua origem o objetivo de atender a uma necessidade especifica de um grupo de integrantes - indivíduos, grupos ou empresas - e, para sua instalação e funcionamento, deve definir o conjunto de arranjos estruturas e práticas que definirá a alocação de poderes sobre a organização que the permitirá cumprir sua missão, passando pela definição de objetivos, políticas e filosofias administrativas"11.

O Instituto Brasileiro de Governança Corporativa, em seu Código, define Governança Corporativa como sendo:

\begin{abstract}
"o sistema pelo qual as organizações são dirigidas, monitoradas e incentivadas, envolvendo as práticas e os relacionamentos entre proprietários, conselho de administração, diretoria e órgãos de controle. As boas práticas de Governança Corporativa convertem princípios em recomendações objetivas, alinhando interesses com a finalidade de preservar e otimizar o valor da organização, facilitando seu acesso ao capital e contribuindo para a sua longevidade" ${ }^{12}$
\end{abstract}

As boas práticas de governança devem ser estruturadas de acordo com as necessidades e a realidade de cada entidade. Para tal, cabe explicitar ${ }^{13}$ os 04 (quatro) pilares fundamentais da governança, já mencionados anteriormente:

\footnotetext{
${ }^{10}$ Salamon Apud TSAI, P. Y.; YAMAMOTO, M. M. Governança corporativa: Análise comparativa entre o setor privado e o terceiro setor. Anais Congresso Contabilidade e Controladoria - USP, São Paulo, Outubro/2005.

${ }^{11}$ FONTES FILHO, Joaquim Rubens. O que podemos aprender com a governança das organizações públicas e não empresariais. In O futuro da Governança Corporativa. Org. FONTES FILHO, Joaquin Rubens e LEAL, Ricardo Pereira Câmara. Saint Paul: São Paulo, 2003, p. 270.

${ }^{12}$ INSTITUTO BRASILEIRO DE GOVERNANÇA CORPORATIVA (IBGC). Código das melhores práticas de governança corporativa. 4.ed. Instituto Brasileiro de Governança Corporativa. São Paulo: IBGC, 2009. Disponível em: <http://www.ibgc.org.br/inter.php?id=18180\&email>. Capturado em 21/04/2015.

${ }^{13}$ ROSSETTI, José Paschoal. ANDRADE, Adriana. Op. Cit.,pp.141/142.
} 
1. Integridade ética (fairness), presente em todos os sistemas de relações internas e externas, entendido também como senso de justiça, no atendimento às expectativas e às demandas de todos os "constituintes organizacionais";

2. Transparência das informações (disclosure): especialmente daquelas de alta relevância, potencialmente causadoras de impactos e que envolvem riscos;

3. Prestação responsável de contas (accountability): fundamentada nas melhores práticas contábeis e de auditoria e com exatidão, tida por fundamental para a confiabilidade na gestão;

4. Conformidade (compliance) com instituições legais e com os marcos regulatórios, dentro dos quais se exercerão as atividades da OTS.

Além dos valores acima, que integram a base ética da organização sem fins lucrativos, mas não a esgotam, existem outros elementos que visam estruturar os mecanismos de governança de forma eficiente.

O primeiro elemento é a propriedade, no sentido de que "um dos principais atributos que diferenciam as razões de ser e as diretrizes da governança corporativa é a estrutura de propriedade nas companhias, bem como o regime legal de sua constituição"14.

No caso das organizações sem fins lucrativos, não existe uma distribuição de propriedade propriamente dita. No entanto, deve observar-se a forma jurídica mais adequada para sua constituição (associação, fundação), e se tal forma atenderá aos seus fins sociais. Logicamente, essa averiguação prévia é factível em organizações a serem constituídas, mas ela não perde importância durante a vida da entidade, como é o caso de haver associado que seja servidor público ${ }^{15}$, a fim de evitar-se, por exemplo, futura situação de irregularidade que possa prejudicar a OTS. No elemento propriedade também se insere a forma de alocação dos recursos angariados pela entidade, vez que a distribuição entre seus membros encontra restrições legais.

O segundo elemento são os princípios que, nas entidades do terceiro setor, muitas vezes, guardam identidade com a sua finalidade social. Os quatro pilares acima descritos inserem-se neste elemento e constituem o núcleo inegociável da base ética da governança ${ }^{16}$.É essencial que exista um Código de Conduta ou de Ética, por escrito, distribuído para os funcionários e colaboradores, bem como disponível para consulta do públicoem geral.

Os princípios devem permear toda a atividade da entidade e, se acaso estiverem sendo desrespeitados, deverá haver uma revisão das práticas ${ }^{17}$ adotadas pela OTS. À título exemplificativo, o relatório Fasfil, já citado,

\footnotetext{
${ }^{14}$ ROSSETTI, José Paschoal. ANDRADE, Adriana. Op. Cit., p.143

${ }^{15}$ Como, por exemplo, a controvertida questão da remuneração de servidor público; a própria incompatibilidade com o cargo público, porque proibido por lei ou pelo estatuto; porque o cargo público exige dedicação exclusiva; por eventual conflito de interesses, dentre vários outros.

${ }^{16}$ ROSSETTI, José Paschoal. ANDRADE, Adriana. Op. Cit., p.145

${ }^{17}$ O Principles for Good Governance and Ethical Practice A Guide for Charities and Foundations (2005), elaborado pelo Independent Sector, aponta que "Strengthening ethics and accountability is an organic process that requires an ongoing commitment by boards and staff of individual organizations and by the entire nonprofit community. It is advisable that an
} 
mostrou discrepâncias na remuneração média das mulheres, que pode chegar a equivaler a 75,2\% da remuneração média dos homens ${ }^{18}$. Ora, corrigir eventuais distorções ${ }^{19}$ internas deste tipo deveria ser pauta nas OTS, sob risco de comprometer a baseética.

Outro elemento é a definição dos direcionamentos estratégicos da entidade. Observe-se que, nas OTS, os propósitos, ou missão, são o vaso condutor da própria existência da entidade, cuja preservação deve ter-se por norte.

Além disso, as boas práticas de governança recomendam a previsão do funcionamento da estrutura de poder, ou seja, a forma em que se articulam as negociações e se estabelecem as relações entre os órgãos de governança, de forma a minorar eventuais disputasfuturas.

Neste diapasão, o bom funcionamento da estrutura de poder depende da separação do rol desempenhado por cada órgão integrante da entidade ${ }^{20}$. Também se insere neste elemento o processo de:

"escolha e disponibilidade de representantes ou conselheiros - se eleitos por grupos, quais os prazos de mandato, possibilidade de recondução, critérios de inexigibilidade, exoneração, forma de definição da presidência, dentre outros - e a utilização e composição de instâncias de apoio à deliberação estratégica"21.

É essencial a definição do papel do Conselho de Administração, cuja eficiência, por vezes, é de complexa mensuração. Dada a ausência de lucro propriamente dito a ser extraída da atividade, estabelecer indicadores de desempenho individuais ou organizacionais ligados ao objeto de atuação social pode não ser tarefa simples. Assim, caberá à entidade avaliar se o conselho deve compor-se de pessoas relevantes sob a ótica do levantamento de fundos, ou se o papel estratégico na administração da entidade é mais importante (nem sempre uma pessoa influente, capaz de angariar fundos para a entidade deterá a expertise de um administrador, evice-versa).

\footnotetext{
organization's board conduct a thorough discussion of the complete set of principles, and determine how the organization should apply each to its operations. It is possible that after this review, a board may conclude that certain principles do not apply to its organization. Developing a transparent process for communicating how the organization has addressed the principles, including the reasons that any of the principles are not relevant, is likely to foster a greater appreciation of the diverse nature of the sector and a deeper respect for the board's good stewardship." Embora referido Guia contenha disposiçōes diversas além dos princípios que devem reger uma entidade sem fins lucrativos, a realidade é a de ajustar tanto tais valores (normalmente ampliando-os), assim como policiar que as atividades da entidade não contrariem tais princípios. Disponível em http://www.hewlett.org/uploads/files/Principles_Guide.pdf,capturado em 07/01/2015.

${ }^{18}$ Fasfil, op. cit., p. 54.

${ }^{19} \mathrm{O}$ princípio n. 11 do Principles for Good Governance and Ethical Practice prevê que "The board of a charitable organization should include members with the diverse background (including, but not limited to, ethnicity, race, and gender perspectives), experience, and organizational and financial skills necessary to advance the organization's mission", o u seja, existe uma preocupação por superar os desacertos oriundos de discriminação por gênero ou raça na alta direção.

${ }^{20}$ Aqui é importante avaliar as responsabilidades dos conselhos; periodicidade das reuniões, tamanho e estrutura do CA e demais órgãos; a independência dos conselhos; etc. Cada entidade, de acordo com o tamanho, recursos de que dispõe, atividades que desempenha, deverá avaliar estas questões casuisticamente, sempre sujeitas a revisão periódica.

${ }^{21}$ FONTES FILHO, Joaquim Rubens. Op. Cit., p.275.
} 
Outro elemento são as bases práticas, que remetem à capacidade de gestão ${ }^{22}$, como uma forma de alcançar a consecução de seu fim social, definindo e traçando metas compatíveis com a realidade da entidade, pois o "principal gestor deve, portanto, ter a capacidade de otimizar a alocação e uso dos recursos da organização para alcançar seus objetivos"23. Muito importante, nas entidades sem fins lucrativos, é manter uma política ${ }^{24}$ responsável de captação de recursos.

Ocorre que nem sempre a eficácia, entendida como a consecução dos objetivos sociais, e a eficiência, vista como a melhor utilização dos recursos, estarão alinhadas. Joaquim Fontes brinda o exemplo do executivo de uma $O N G$, cuja agenda principal é a luta por melhores condições de trabalho, que não confere primazia a tal valor fundamental perante outros critérios de eficiência, realizando demissões ${ }^{25}$. Como complemento a esta ideia, devese manter especial cuidado na escolha dos parceiros, em vista da responsabilidade objetiva prevista no art. $2^{\circ}$, da Lei n. 12.846/2013, como será visto adiante.

Por isso, as práticas de gestão, em especial as de alto impacto, devem ser decididas, homologadas e monitoradas. $\mathrm{O}$ controle interno e externo ${ }^{26}$, com a realização de auditorias, é um dos ingredientes essências da boa gestã $0^{27}$, além da transparência em todas as fases do processo.

O modelo de estrutura de propriedade ${ }^{28}$ das pessoas jurídicas com fins lucrativos, sob a ótica da possibilidade de melhores monitoramento e alinhamento entre gestores e principais atores pode ser trazido também para o âmbito das OTS. No entanto, apontam Herrero, Cruz e Merino a inexistência de comprovação de que um grande doador vinculado à entidade (modelo de estrutura concentrada) redunde em melhor monitoramento da mesma ${ }^{29}$. Contrapõem-se a esta assertiva Mendonça e Machado Filho, pontuandoque:

"nas OTS com grandes instituidores o risco de não-alinhamento seria menor, pois o instituidor teria maiores incentivos para monitorar o gestor. No caso de uma organização com doadores dispersos, o incentivo de cada doador para monitorar a utilização dos recursos seria comparativamente menor. Em uma organização de Terceiro Setor que se

\footnotetext{
${ }^{22} \mathrm{~A}$ implementação do programa de compliance, com mecanismos de monitoramento de atendimento à lei; estipulação de política de brindes, reembolso de despesas, whistleblower, conflito de interesses...

${ }^{23}$ FONTES FILHO, Joaquim Rubens. Op. Cit., p.275.

${ }^{24}$ Sem pretender esgotar o assunto, podemos citar: usar as contribuição de acordo com a intenção do doador; usar material informativo (seja por telefone, escrito, ou qualquer outro) que espelhe a realidade das atividades da entidade; respeitar o anonimato dos doadores (com as exceções legais), além de vários outros.

${ }^{25}$ FONTES FILHO, Joaquim Rubens. Op. Cit., p. 276.

${ }^{26}$ A legislação envolvendo o relacionamento com a administração pública apesenta diversos mecanismos de controle externo, o que foi objeto de estudo no capítulo anterior.

${ }^{27}$ Ocorre que nem sempre as entidades possuem recursos para a contratação de auditores externos, ou mesmo internamente as olha de funcionários deve ser enxugada ao máximo. Aliás, problemas de orçamento são uma realidade que assola a maioria das entidades sem fins lucrativos.

${ }^{28}$ Explicam MENDONÇA, Luciana Rocha de. MACHADO FILHO, Cláudio Antonio Pinheiro. Governança nas organizações do terceiro setor: considerações teóricas. Revista de Administração da USP, São Paulo, v.39, n.4, p.302-308, out./nov./dez. 2004, p. 306, que no modelo de estrutura dispersa, o conflito de interesses ocorre entre os investidores externos (acionistas dispersos) e os gestores. Na hipótese da estrutura de propriedade concentrada, o conflito se dá entre os acionistas controladores e os acionistas minoritários.

${ }^{29}$ apud MENDONÇA, Luciana Rocha de. MACHADO FILHO, Cláudio Antonio Pinheiro. Op. cit., p.306.
} 
mantém com recursos de doadores dispersos, predomina entre eles a hipótese de que os gestores irão alocar os recursos da forma mais eficiente possível, mas isso não é assegurado por amplo monitoramento por parte dos principais. Nesse caso, mecanismos de governança para reduzir o conflito de interesses entre doadores e gestores podem ser caracterizados como um típico problema de ação coletiva dos doadores" ${ }^{\prime 30}$.

Rossetti e Andrade ${ }^{31}$ agregam mais dois elementos que objetivam estruturar as boas práticas de governança, quais sejam, a perenidade e as pessoas.

A perenidade gira em torno não só das práticas de gestão, que garantirão a vida da entidade, mas também perpassa pelas questões atinentes a sucessão, controle de poder, etc. A realidade mostra organizações sem fins lucrativos que enfrentaram inúmeros reveses e existem há décadas, cujos fundadores já deixaram de figurar na alta gestão, o que demonstra que a perpetuidade da entidade é possível, embora seja um desafioenorme.

O elemento "pessoas" é apontado como o componente essencial dos sistemas de governança. Nas entidades sem fins lucrativos, que dependem muitas vezes do trabalho voluntariado, por exemplo, referido elemento ganha mais força, pela necessidade da continua adesão.

Internamente, a coesão de todos que participam das atividades da entidade quanto ao respeito e implementação das práticas de governança é essencial. Para que isso possa acontecer, o comprometimento com as boas práticas de governança deve advir da mais alta administração, e os princípios e mecanismos serem divulgados para todos aqueles que dela participam.

\section{O RELACIONAMENTO DAS ORGANIZAÇÕES DO TERCEIRO SETOR COM A ADMINISTRAÇÃO PÚBLICA E AS EXIGENCIAS LEGAIS SOB A ÓTICA DAS BOAS PRÁTICAS DE GOVERNANÇA.}

O marco regulatório do setor destina-se, precipuamente, às entidades que desejem relacionar-se com a administração pública, contendo normativa bastante ampla. Diante da impossibilidade de esgotar-se a disciplina legislativa, serão trazidas para breve estudo aquelas consideradas mais significativas.

Com o advento da Lei n. 9.637/98, foram instituídas, no âmbito federal ${ }^{32}$, as Organizações Sociais (OS), com o escopo de gerir serviços públicos por delegação do ente federativo. O termo Organização Social corresponde a uma qualificação conferida pela União a entidades de direito privado que atuem nas áreas de ensino, pesquisa científica, desenvolvimento tecnológico, proteção e preservação do meio ambiente, cultura ou saúde.

\footnotetext{
${ }^{30}$ MENDONÇA, Luciana Rocha de. MACHADO FILHO, Cláudio Antonio Pinheiro. Op. cit., p.306.

${ }^{31}$ ROSSETTI, José Paschoal. ANDRADE, Adriana. Op. Cit., p.145/146.

${ }^{32} \mathrm{Na}$ esfera estadual também há previsão legislativa para as Organizações Sociais, como no Estado de São Paulo, onde as OS estão disciplinadas pela Lei Complementar n846/98.
} 
Embora alvo de constantes (e, por vezes, justificadas) $\operatorname{criticas}^{33}$, em especial com relação à ausência de previsão de licitação ${ }^{34}$ para a escolha da entidade que vai receber a qualificação de OS e celebrar o contrato de gestão, a lei contém diversos dispositivos (embora insuficientes sob tal ótica) que vão ao encontro das boas práticas de governança, como: a constituição obrigatória de diretoria e de conselho de administração, com descrição minuciosa da composição e atribuições deste último; proibição de distribuição de bens ou de parcela do patrimônio líquido, em qualquer hipótese; publicidade do contrato de gestão ${ }^{35}$; o controle externo da execução do contrato pelo órgão do Poder Público concedente como mecanismo de gestão; e, do ponto de vista da transparência, a obrigatoriedade de publicação anual dos relatórios financeiros e do relatório de execução do contrato.

A Lei n. 9.790/9936, por sua vez, disciplina as Organizações da Sociedade Civil de Interesse Público (OSCIP). Trata-se, assim, como as OS, de qualificação conferida pelo Ministério da Justiça à pessoa jurídica de direito privado, constituída pela iniciativa privada, sem objetivo de lucro, excluídas todas aquelas que se dediquem às atividades listadas no art. $2^{2}$ da Lei.

A lei em comento institui o Temo de Parceria, instrumento passível de ser firmado com o Poder Público, cuja finalidade é fomentar o exercício de atividades de interesse público por entidades privadas, e não a transferência da prestação do serviço, como é o caso das OS.

A Lei das OSCIP também tem recebido críticas ${ }^{37}$ ferrenhas, em especial quanto à possibilidade de burlar o sistema de controle na escolha dos entes conveniados, por não existir exigência de certame licitatório.

\footnotetext{
${ }^{33}$ Argumenta-se que, sob a alegação da busca da maior eficiência no atendimento, a lei permite elidir a observância do regime jurídico do direito público, embora as OS administrem patrimônio público.

${ }^{34} \mathrm{O}$ Supremo Tribunal Federal, em acordão pendente de publicação, julgou procedente em parte a Ação Direta de Inconstitucionalidade n. 1923/98, para "conferir interpretação conforme à Constituição à Lei no 9.637/98 e ao art. 24, XXIV da Lei n $8.666 / 93$, incluído pela Lei no $9.648 / 98$, para que: (i) o procedimento de qualificação seja conduzido de forma pública, objetiva e impessoal, com observância dos princípios do caput do art. 37 da Constituição Federal, e de acordo com parâmetros fixados em abstrato segundo o que prega o art. 20 da Lei no 9.637/98; (ii) a celebração do contrato de gestão seja conduzida de forma pública, objetiva e impessoal, com observância dos princípios do caput do art. 37 da Constituição Federal; (iii) as hipóteses de dispensa de licitação para contratações (Lei no 8.666/93, art. 24, XXIV) e outorga de permissão de uso de bem público (Lei no 9.637/98, art. $12, \mathbb{S} 3^{\circ}$ ) sejam conduzidas de forma pública, objetiva e impessoal, com observância dos princípios do caput do art. 37 da Constituição Federal; (iv) os contratos a serem celebrados pela Organização Social com terceiros, com recursos públicos, sejam conduzidos de forma pública, objetiva e impessoal, com observância dos princípios do caput do art. 37 da Constituição Federal, e nos termos do regulamento próprio a ser editado por cada entidade; (v) a seleção de pessoal pelas Organizaçōes Sociais seja conduzida de forma pública, objetiva e impessoal, com observância dos princípios do caput do art. $37 \mathrm{da} \mathrm{CF}$, e nos termos do regulamento próprio a ser editado por cada entidade; e (vi) para afastar qualquer interpretação que restrinja o controle, pelo Ministério Público e pelo Tribunal de Contas da União, da aplicação de verbas públicas".

${ }^{35} \mathrm{O}$ contrato deve ser elabora pautado nos princípios da legalidade, impessoalidade, moralidade, publicidade, economicidade.

${ }^{36}$ Referida lei é regulamentada pelo Decreto n 3.100, de 30/06/99.

${ }^{37}$ São diversas, podendo citar, dentre outras: ausência de prazo para duração da parceria; a malsinada inexistência de previsão de licitação para escolha da entidade parceira; suposta burla ao sistema de concurso público, por estarem sendo utilizadas para fornecer mão de obra para a Administração Pública; contratação com entidades que inserem em seu objeto social todas as atividades previstas no art. $3^{\circ}$ da lei, o que, segundo os críticos, desvirtua a eficiência que não se conseguiu atingir com a execução via Administração Pública. Com relação a esta última, a Lei n. 13.019/14 tentou contornar tais críticas, tendo introduzido a seguinte alteração no art. ${ }^{\circ}$ da Lei: "Podem qualificar-se como Organizações da Sociedade Civil de Interesse Público as pessoas _vol.09, n. 02, Rio de Janeiro, 2016. pp. 1012-1030 1020
} 
No entanto, do ponto de vista da transparência, controle externo e interno e publicidade, a referida lei introduz mecanismos de controle importantes para adoção das melhores práticas degovernança.

Na mesma linha das OS, a Lei determina que as OSCIP observem os princípios da legalidade, impessoalidade, moralidade, publicidade, economicidade e da eficiência (art. $4^{\mathrm{a}}$, I), ou seja, ainda que se trate dos princípios que regem a Administração Pública, podem ser considerados parte do núcleo de princípios éticos que regem as boas práticas de governança. A Lei também é clara quanto à proibição de distribuir:

"entre os seus sócios ou associados, conselheiros, diretores, empregados ou doadores, eventuais excedentes operacionais, brutos ou líquidos, dividendos, bonificações, participações ou parcelas do seu patrimônio, auferidos mediante o exercício de suas atividades"

sendo obrigatório seu retorno para aplicação integral na consecução do objeto social (art. $1^{\circ}, \$ 1^{\circ}$ ).

A Lei das OSCIP não contém determinação expressa de constituição de conselho de administração. No entanto, contempla outros mecanismos de controle (art. $4^{\circ}$ ), tornando obrigatória:

"a adoção de práticas de gestão administrativa, necessárias e suficientes a coibir a obtenção,
de forma individual ou coletiva, de benefícios ou vantagens pessoais, em decorrência da
participação no respectivo processo decisório", bem como a constituição de "conselho fiscal
ou órgão equivalente, dotado de competência para opinar sobre os relatórios de
desempenho financeiro e contábil, e sobre as operações patrimoniais realizadas, emitindo
pareceres para os organismos superiores da entidade"

Com relação à transparência e controle das contas e na execução dos serviços, a lei prevê: a observância dos princípios fundamentais e normas brasileiras de contabilidade; a publicidade do relatório de atividades e das demonstrações financeiras da entidade, "colocando-os à disposição para exame de qualquer cidadão"; a realização de auditoria, inclusive externa, se preciso; a prestação de contas de todos os recursos e bens de origem pública $\operatorname{recebidos}^{38}$; a fiscalização e avaliação da execução da parecia pelo Poder Público; além da publicação de regulamento próprio contendo os procedimentos que adotará para a contratação de obras e serviços, bem como para compras com emprego de recursos provenientes do Poder Público.

Por fim, cabe trazer à baila a Lei n. 13.019/2014, que trata do regime jurídico das parcerias voluntárias (termo de colaboração e termo de fomento), envolvendo ou não transferência de recursos financeiros entre a Administração Pública e as denominadas Organizações da Sociedade Civil(OSC).

Diferente do marco regulatório das OS e OSCIP, a Lei 13.019/2014 não exige qualquer tipo de certificação prévia para que a entidade possa firmar Termos de Colaboração ou Fomento, bastando ser Organização da Sociedade Civil, nos termos da lei, e cumprir os demais requisitos de participação nela previstos.

jurídicas de direito privado sem fins lucrativos que tenham sido constituídas e se encontrem em funcionamento regular há, no mínimo, 3 (três) anos, desde que os respectivos objetivos sociais e normas estatutárias atendam aos requisitos instituídos por esta Lei".

${ }^{38} \mathrm{Na}$ forma do art. 70, parágrafo único, da Constituição Federal. 
Importante destacar o art. 24 da lei, que estabelece o "chamamento prévio" para a celebração dos Termos acima mencionados, conferindo, assim, maior transparência na escolhadas OSC.

Ainda sobre transparência e publicidade, a referida norma determina que a OSC deverá divulgar na internet e em sua sede todas as parcerias celebradas com o Poder Público. O art. 11, § único, IV, determina que seja divulgado também "valor total da parceria e valores liberados, quando for o caso".

Fato é que a lei demonstra preocupação com eventuais desvios de verba ou de finalidade das OSC. Além de um capitulo destinado aos atos de improbidade administrativa, que promoveu ampliação sensível à Lei n. 8.429/92, estipula a criação de um canal de denúncias, cabendo à Administração Pública divulgar, pela internet, os meios para apresentação de representação sobre a aplicação irregular dos recursos transferidos (art. 12).

Outro ponto relevante trazido pela Lei é a possibilidade de atuação de duas ou mais OSC em rede (art. 35- $\left.\mathrm{A}^{39}\right)$. Tal colaboração vislumbra-se como um dos pontos sensíveis das organizações, face às previsões contidas na Lei Anticorrupção (Lei n. 12.846/2013), pois a responsabilidade objetiva da pessoa jurídica, prevista no art. 2º da Lei, refere-se aos atos lesivos "praticados em seu interesse ou benefício, exclusivo ou não".

Ou seja, o cuidado nas parcerias firmadas e o controle das atividades dos parceiros deverá ser redobrada, uma vez que, em virtude da responsabilidade objetiva, eventual falta de zelo na escolha dos funcionários ou colaboradores, ou mesmo no monitoramento/controle das atividades por estes exercidas, a OSC poderá ver aplicado o rigor da lei em seu desfavor.

Vemos, assim, que uma política efetiva de compliance ainda nesta fase mostra-se essencial para salvaguardar os interesses das OSC e, consequentemente, de seus gestores.

\section{APLICAÇÃO DA LEI N. 12. 846 / 2013 ẢS ENTIDADES DO TERCEIRO SETOR. IMPORTÂNCIA DA ADOÇÃO DE UM PROGRAMA DE COMPLIANCE EFETIVO.}

As entidades sem fins lucrativos que lidam com verbas públicas não têm se mostrado imunes ao envolvimento em diversos esquemas de corrupção ao longo dotempo.

Como explicam ${ }^{40}$ Helena Helmer e StuartDelming:

"Many NGOs, especially those providing humanitarian assistance and engaged in development projects, operate in developing countries where they face the same risks as traditional business organizations. One of those risks is corruption. NGOs face two kinds of corruption-related risks. One is the risk of becoming an offender by paying a bribe to a

\footnotetext{
39 “Art. 35-A. É permitida a atuação em rede, por duas ou mais organizações da sociedade civil, mantida a integral responsabilidade da organização celebrante do termo de fomento ou de colaboração, desde que a organização da sociedade civil signatária do termo de fomento ou de colaboração possua (...)"

${ }^{40}$ HELMER, Elena. DEMING, Stuart H. Non-Governmental Organizations: Anticorruption Compliance Challenges and Risks. The International Lawyer. Vol. 45, No. 2 (SUMMER 2011), pp. 597-624. Disponível em: <http://www.deminggroup.com/Michigan-Practice/Publications/Non-Governmental-Organizations-AnticorruptionChallenges-and-Risks.pdf>, acessado em 10/02/2015.
} 
government official, violating the FCPA or other anti-bribery laws. The other risk is becoming a victim of corruption, such as when the funds or assets of an NGO are misappropriated or otherwise misused."

O relacionamento ${ }^{41}$ de tais entidades com a Administração Pública, como acima anunciado, reveste-se de certos formalismos que lhe são peculiares, o que, por vezes, redunda na excessiva burocratização.

Quanto à correlação entre burocracia em demasia e corrupção, destaca Elisabete Ferrarezi a distorção na:

"crença de que sucessivas barreiras burocráticas dificultariam a ocorrência de favoritismo, quando se sabe que quanto mais dificuldades burocráticas são acrescidas, mais riscos de tráfico de influências"42. A doutrina (e o mercado) costuma referir-se ao "Elevado "Custo Regulatório" do País, assim considerado o internalizado pelas sociedades para fazer frente ao excesso de burocracia estatal (v.g., pela necessidade da obtenção das mais variadas licenças para o exercício de determinada atividade econômica, pela profusão de normas regulatórias que criam barreiras à entrada em diversos setores da economia, pela sobreposição de agentes fiscalizadores)"43.

Neste esteio, a Lei Anticorrupção vem compor o chamado "sistema legal de defesa da moralidade" 44 , que contém, dentre outras, a Lei no 8.429/1992 e a própria Lei n. 8666/93. Mas, a disciplina da Lei 12.846/2013 inova totalmente, não só do ponto de vista das sanções e punições, como também seu alcance extraterritorial.

Logo em seu art. 1\%, a lei delimita seu objeto: a responsabilização objetiva administrativa e civil ${ }^{45}$ de pessoas jurídicas pela prática de atos contra a Administração Pública, nacional ou estrangeira. Em seu parágrafo único, não deixa espaço para dúvidas quanto à sua aplicação às OTS, vez que se refere a "quaisquer fundações, associações de entidades ou pessoas (...) que tenham sede, filial ou representação no território brasileiro, constituídas de fato ou de direito, ainda que temporariamente” (grifou-se). Assim, qualquer entidade sem fins

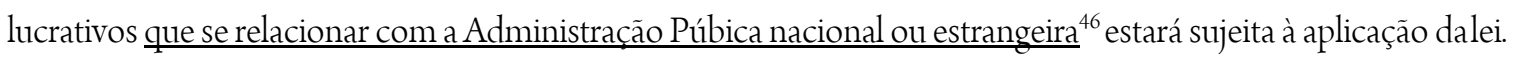

\footnotetext{
${ }^{41} \mathrm{O}$ relacionamento com a administração pública pode tomar contornos diversos, não se restringindo à realização de parcerias, a exemplo de eventual desvio de verba oriunda de isenção tributária; oferecimento ou pagamento de vantagem indevida a agente público, ou a terceira pessoa a ele relacionada, para conseguir a liberação de uma licença, dentre outros. A lista exemplificativa é infinita.

${ }^{42}$ FERRAREZI, Elisabete Roseli. Op. cit. p. 128.

${ }^{43}$ MOREIRA NETO, Diogo de Figueiredo. FREITAS, Rafael Véras de, A juridicidade da Lei Anticorrupção - Reflexões e interpretações prospectivas. Revista Forum Administrativo. fev. 2014, p.03.

${ }^{44}$ MOREIRA NETO, Diogo de Figueiredo. FREITAS, Rafael Véras de. Op. cit. p. 03.

${ }^{45}$ Não pretendemos esgotar o assunto da lei anticorrupção neste trabalho, cabendo apontar que referida lei estipula o regime de independência de instâncias para fins de punibilidade, previsto nos arts. $3^{\circ}, 18$ e 30.

${ }^{46} \mathrm{O}$ art. $5^{\mathrm{a}}$, $\$ \$ 2^{\circ}$ e $3^{\circ}$, consideram "administração pública estrangeira os órgãos e entidades estatais ou representações diplomáticas de país estrangeiro, de qualquer nível ou esfera de governo, bem como as pessoas jurídicas controladas, direta ou indiretamente, pelo poder público de país estrangeiro", além das "organizações públicas internacionais". Cabe recordar que a transferência de recursos de governos estrangeiros para ONGs brasileiras é de longa data. O governo alemão, por exemplo, colaborou com projeto de demarcação de terras indígenas no "Médio e Alto Rio Negro e no Alto Solimões, na segunda metade dos anos noventa, e conduzido sob a coordenação de uma ONG brasileira e a supervisão da agência de cooperação técnica daquele país. Trata-se de projeto que envolveu um montante de recursos de duas dezenas de milhões de euros, e que foi responsável pela demarcação de terras indígenas compreendendo um total de mais de $200.000 \mathrm{Km}^{2}$, uma área equivalente ao estado de São Paulo”. COSTA, Wanderley Messias da Fonte. O Brasil e a América do Sul: cenários geopolíticos e os desafios da integração. Confins [Online], 7/2009, posto online em 31/10/2009. Disponível em: <http://www.uel.br/cce/geo/didatico/omar/brasil_america_sul.pdf>. Capturado em 25/01/2015.
} 
O art. 28 da lei vai além, responsabilizando as pessoas jurídicas brasileiras ${ }^{47}$ cujos atos lesivos, praticados em desfavor da Administração Pública estrangeira tenham sido cometidos no exterior ${ }^{48}$.

A normativa em tela não exige, para fins de responsabilização, que tenha sido auferido um benefício direto, bastando que o ato lesivo tenha sido praticado em seu interesse, exclusivo ou não (benefício indireto). Como se trata de responsabilidade objetiva $\left(\operatorname{art.} 2^{\circ}\right)$, bastará a comprovação do ato de corrupção e o nexo de causalidade com a conduta do agente.

Como explicam Diogo de Figueiredo e RafaelFreitas:

"A ratio desse dispositivo é, claramente, fomentar que as pessoas jurídicas, elas próprias, instituam sistemas de controle sobre as condutas de seus agentes, de que evitem a prática de atos violadores da moral administrativa, uma vez que lhes será impossível isentarem-se de eventual responsabilização alegando ausência de culpa invigilando" ${ }^{\text {"49 }}$.

Entendemos que a motivação também perpassa pela gestão eficiente dos riscos na escolha dos colaboradores (culpa in eligendo).

Com relação aos atos lesivos, como se vê do art. $5^{\text {a }}$, a lista é extensa, conferindo especial atenção às práticas ilícitas, com o objetivo de fraudar licitações. Cabe observar, como já dito, as alterações introduzidas pela Lei n. 13.019/2014 ${ }^{50}$ ao art. 10 da Lei de Improbidade, que incluiu no rol dos atos deimprobidade:

Art. $10(\ldots)$ :

VIII - frustrar a licitude de processo licitatório ou de processo seletivo para celebração de parcerias com entidades sem fins lucrativos, ou dispensá-losindevidamente;

XVI - facilitar ou concorrer, por qualquer forma, para a incorporação, ao patrimônio particular de pessoa física ou jurídica, de bens, rendas, verbas ou valores públicos transferidos pela administração pública a entidades privadas mediante celebração de parcerias, sem a observância das formalidades legais ou regulamentares aplicáveis à espécie;

XVII - permitir ou concorrer para que pessoa física ou jurídica privada utilize bens, rendas, verbas ou valores públicos transferidos pela administração pública a entidade privada mediante celebração de parcerias, sem a observância das formalidades legais ou regulamentares aplicáveis à espécie;

XVIII - celebrar parcerias da administração pública com entidades privadas sem a observância das formalidades legais ou regulamentares aplicáveis à espécie;

XIX - agir negligentemente na celebração, fiscalização e análise das prestações de contas de parcerias firmadas pela administração pública com entidades privadas;

XX - liberar recursos de parcerias firmadas pela administração pública com entidades privadas sem a estrita observância das normas pertinentes ou influir de qualquer forma para a sua aplicação irregular;

\footnotetext{
${ }^{47}$ Com relação à aplicação do Foreign Corrupt Practices Act às OTS, vide HELMER, Helena e DEMING, Stuart H., Op. Cit., pp. 602/603: "Under the FCPA, mere status as an NGO does not exempt an entity from being subject to the anti-bribery provisions. NGOs fall into the category of "domestic concerns" subject to the anti-bribery provisions. No legal basis exists for distinguishing between a traditional commercial enterprise and an NGO in determining what qualifies as a "domestic concern." No "carve out," "safe harbor," or other express exception exists, nor does an exception exist for an NGO that is strictly charitable in nature."

${ }^{48} \mathrm{~A}$ atuação de entidades brasileiras sem fins lucrativos no exterior também se faz presente, muitas vezes para auxiliar em situações episódicas, como no Haiti após o terremoto que assolou o país em 2010. Diversas ONGs angariaram fundos ou mesmo enviaram missões humanitárias.

${ }^{49}$ MOREIRA NETO, Diogo de Figueiredo. FREITAS, Rafael Véras de. Op. cit. pp.7/8.

${ }^{50}$ Alterada pela Lei n. 13.204, de 14 de dezembro de 2015.
} 
XXI - liberar recursos de parcerias firmadas pela administração pública com entidades privadas sem a estrita observância das normas pertinentes ou influir de qualquer forma para a sua aplicação irregular.

Embora a Lei Anticorrupção não faça referência expressa à Lei n. 13.019/2014, entendemos que a legislação deve ser vista de forma conglobante, por tudo exposto acima (e, em especial, as disposições introduzidas na Lei de Improbidade Administrativa), com plena aplicação às Organizações do Terceiro Setor.

Ou seja, resta claro que o dever de monitoramento é indispensável, de forma a coibir eventuais desvios de conduta de funcionários, gerentes, ou mesmo da alta administração. Como exemplo de situações de risco, temos a excessiva liberdade que eventualmente possa ser dada a terceiros encarregados de dar andamento a trâmites burocráticos junto a órgãos da Administração Pública ${ }^{51}$. Aos olhos da Lei Anticorrupção, a entidade também poderá vir a ser responsabilizada pelos atos lesivos por elespraticados.

Neste diapasão, o destaque da Lei Anticorrupção é o reconhecimento de que a existência de um programa efetivo de compliance (mecanismos e procedimentos internos de integridade, auditoria e incentivo à denúncia de irregularidades e a aplicação efetiva de códigos de ética e de conduta no âmbito da pessoa jurídica) poderá influenciar na aplicação da sanção administrativa ${ }^{52}$.

A regulamentação da Lei Anticorrupção tampouco deixa espaço para dúvidas quanto à importância de se ter um programa de compliance efetivo. O Decreto n. 8.420/2015, além de reforçar a sua influência na "dosimetria das sanções a serem aplicadas", dispensa um capítulo inteiro ao chamado "Programa de Integridade" cujos parâmetros de avaliação são bastante extensos.

Numa primeira leitura, as OTS podem se deixar impressionar pelo nível de exigência, e, em especial, dos aparentes custos envolvidos em criar um departamento de compliance, à luz do disposto no art. 42 , IX ${ }^{54}$, ou mesmo na implantação de um canal de denúncias (art. 42, $\mathrm{X}^{55}$ ), especialmente porque a grande maioria das organizações estão lutando para angariar fundos em prol da consecução de seu fim social, vez que inseridas em um ambiente de fund raising bastante competitivo. Mas o art. 41, $\$$ único, atento a realidades como a das entidades sem fins lucrativos, estipula que:

\footnotetext{
${ }^{51}$ Não é à toa que o art. 30, da Portaria 909/CGU/2015, sobre a avaliação de programas de integridade de pessoas jurídicas, ao especificar as informações que devem constar no "relatório de perfil", a pessoa jurídica deverá especificar a "frequência e a relevância da utilização de agentes intermediários, como procuradores, despachantes, consultores ou representantes comerciais, nas interações com o setor público."

${ }^{52}$ Art. 70. Serão levados em consideração na aplicação das sanções: (...) VIII - a existência de mecanismos e procedimentos internos de integridade, auditoria e incentivo à denúncia de irregularidades e a aplicação efetiva de códigos de ética e de conduta no âmbito da pessoa jurídica.

${ }^{53}$ No âmbito do Poder Executivo federal e em relação aos atos contra a Administração Pública estrangeira, a Controladoria Geral da União editou a Portaria n. 909, de 07/04/2015, que dispõe sobre a avaliação de programas de integridade de pessoas jurídicas.

${ }^{54}$ IX - independência, estrutura e autoridade da instância interna responsável pela aplicação do programa de integridade e fiscalização de seu cumprimento.

${ }^{55} \mathrm{X}$-canais de denúncia de irregularidades, abertos e amplamente divulgados a funcionários e terceiros, e de mecanismos destinados à proteção de denunciantes deboa-fé;
} 
O programa de integridade deve ser estruturado, aplicado e atualizado de acordo com as características e riscos atuais das atividades de cada pessoa jurídica”, cabendo a esta garantir, no entanto, "o constante aprimoramento e adaptação do referido programa, visando garantir sua efetividade”.

A verdade é que o efeito em cascata proporcionado ${ }^{56}$ pela ausência de política efetiva de compliance pode vir a acelerar e escalonar ainda mais os custos, acaso possa recair sobre a OTS alguma sanção decorrente da pratica de ato de corrupção, e proporcionar danos irreparáveis à reputação da entidade, confiança e crédito com relação aos stakeholders.

\section{CONSIDERAÇÕES FINAIS.}

Como delineado na primeira parte deste trabalho, as Organizações do Terceiro Setor vêm ocupando um papel essencial na sociedade moderna, contribuindo enormemente para a inclusão social e humana dos cidadãos e, portanto, para o desenvolvimento dos países em que atuam.

A importância crescente de tais entidades tem como reflexo o exponencial aumento dos recursos por elas administrados, o que nem sempre vem acompanhado, lamentavelmente, da transparencia necessária no que diz respeito à destinação dos recursos, muito menos ao balanço de seu desempenho social.

Tamanha responsabilidade assumida pelas OTS, podendo considerar-se, de um lado, a responsabilidade social perante a parcela da população beneficiada, e, de outro, a financeira, perante as fontes de financiamento das atividades desempenhadas, merece a reflexão sobre os benefícios da adoção das boas práticas de governança.

Tais questões apresentam-se pari passu ao desenvolvimento da sociedade, em que são estipulados padrões mais elevados de prestação de contas e responsabilidade corporativa. Neste diapasão, algumas Organizações do Terceiro Setor, apesar de desvestidas de atividade lucrativa, têm respondido de forma ativa e responsável perante as expectativas da comunidade. Ocorre que o movimento ainda é restrito às OTS que movimentam recursos mais vultosos ${ }^{57}$.

Os princípios e práticas de boa governança, suscintamente apresentados e sugeridos na segunda parte do texto, objetivam precipuamente implementar mecanismos de transparência e controle, internos e externos, que possam permitir uma gestão mais profissionalizada de tais entidades, atenuando a assimetria informacional e diminuindo os problemas de agência. Podemos dizer que o objetivo precípuo da boa governança é a dar esteio para a efetividade, a credibilidade e a perenidade da organização sem finslucrativos.

A bem da verdade, como restou delineado na terceira parte, atender de forma coesa ao marco regulatório das Organizações do Terceiro Setor, especialmente quando mantêm relações com o Poder Público, demanda a

\footnotetext{
${ }^{56}$ Por questões metodológicas, não foi possível adentrar na questão das pesadas multas administrativas previstas no Decreto $8.420 / 2015$, arts. 17 a 23 .

${ }^{57}$ Algumas organizações, como Médicos sem Fronteiras
} 
introdução e aperfeiçoamento das boas práticas de governança, sempre de acordo com a realidade da atividade desempenhada por ela desempenhada.

O compliance ou conformidade legal, última questão tratada, constitui fundamento basilar das boas práticas de governança. Com a edição da Lei Anticorrupção e legislação correlata, a necessidade de mudança no padrão de governança, no que pertine aos deveres preventivos, mostra-se premente, especialmente por aquelas entidades que lidam diretamente com a Administração Pública. Isto não só do ponto de vista preventivo, no intuito de coibir a prática do ato de corrupção, mas também porque referida lei, como destacado, reconhece que a existência de um programa efetivo de compliance poderá vir ter influência na aplicação de eventual sanção administrativa.

Pelas razões expostas, acreditamos que a adoção de sólidos mecanismos de boas práticas de governança serve não só para assegurar um comportamento ético e confiável da entidade como um todo, mas, igualmente importante, presta-se a contribuir para o atingimento do desempenho social eficiente e, portanto, para a continuidade do amplo apoio dos stakholders e consequente perenidade da Organizações do Terceiro Setor.

\title{
GOOD CORPORATE GOVERNANCE: OBSERVATIONS AND
}

\section{RECOMMENDATIONS FOR THE NON-GOVERNMENTAL ORGANIZATIONS SECTOR. THE IMPORTANCE OF IMPLEMENTING AN E FFECTIVE COMPLIANCE PROGRAM IN ORDER TO ABIDE BY LAW N. 12.846 / 2015.}

\begin{abstract}
This work aims to present and suggest good governance practices that can be applied to Third Sector organizations. Without any means of exhausting the topic, the article points out the potential benefits of adopting transparency and control mechanisms, both internal and external, to allow a more professional management of such entities, since those practices can help reduce information asymmetry and mitigate agency problems, always in the search for efficient social performance. The text also provides an overview of the most relevant laws that regulate nonprofit organizations and analyzes several legal requirements from the perspective of good governance practices. In the end, since compliance can be considered one of the pillars of good governance, the text highlights the importance of adopting an efficient program to abide by Law n. 12.846/2013 and Decree n. 8420/2015.
\end{abstract}

Keywords: Non-governmental organizations; good corporate governance; compliance; anti-corruptionlaw. 


\section{BIBLIOGRAFIA}

BRASIL Banco Nacional do Desenvolvimento (BNDES). Terceiro Setor e desenvolvimento social. AS/GESET RELATO SETORIAL No 3, Julho/2001. Disponível em: <http://www.bndes.gov.br/SiteBNDES/export/sites/default/bndes_pt/Galerias/Arquivos/conhecimento/rel ato/tsetor.pdf>

As Fundações Privadas e Associações sem Fins Lucrativos no Brasil (2010) - FASFIL. Rio de Janeiro: IBGE, 2012. Disponível em<ftp://ftp.ibge.gov.br/Fundacoes_Privadas_e_Associacoes/2010/fasfil.pdf.

Constituição da República Federativa do Brasil de 1988. Disponível em: <http://www.planalto.gov.br/ccivil_03/constituicao/constituicaocompilado.htm>

CONTROLADORIA-GERAL DA UNIÃO (CGU). Portaria n. 909, de 7 de abril de 2015. Dispõe sobre a avaliação de programas de integridade de pessoas jurídicas. Disponível em: <http://www.cgu.gov.br/sobre/legislacao/arquivos/portarias/portaria_cgu_909_2015.pdf>

CONTROLADORIA-GERAL DA UNIÃO (CGU). Portaria n. 910, de 7 de abril de 2015. Define os procedimentos para apuração da responsabilidade administrativa e para celebração do acordo de leniência de que trata a Lei $\mathrm{n}^{\circ} 12.846$, de $1^{\circ}$ de agosto de 2013. Disponível em: <http://www.cgu.gov.br/sobre/legislacao/arquivos/portarias/portaria_cgu_910_2015.pdf>

Decreto no 3.100, de 30 de junho de 1999. Regulamenta a Lei no 9.790, de 23 de março de 1999, que dispõe sobre a qualificação de pessoas jurídicas de direito privado, sem fins lucrativos, como Organizações da Sociedade Civil de Interesse Público, institui e disciplina o Termo de Parceria, e dá outras providências. Disponível em: <http://www.planalto.gov.br/ccivil_03/decreto/d3100.htm>

Decreto $\mathrm{n}^{\circ} 8.420$, de 18 de março de 2015. Regulamenta a Lei $\mathrm{n}^{\mathrm{a}}$ 12.846, de $1^{\text {a }}$ de agosto de 2013. Disponível em:<http://www.planalto.gov.br/ccivil_03/_Ato2015-2018/2015/Decreto/D8420.htm>

Lei no 9.790, de 23 de março de 1999. Dispõe sobre a qualificação de pessoas jurídicas de direito privado, sem fins lucrativos, como Organizações da Sociedade Civil de Interesse Público, institui e disciplina o Termo de Parceria, e dá outras providências. Disponível em: <http://www.planalto.gov.br/ccivil_03/leis/19790.htm>

LLei $\mathrm{n}^{\circ}$ 10.406, de 10 de janeiro de 2002. Institui o Código Civil. Disponível em: <http://www.planalto.gov.br/ccivil_03/leis/2002/110406.htm>

Lei n. 12.846, de $1^{\text {a }}$ de agosto de 2013. Dispõe sobre a responsabilização administrativa e civil de pessoas jurídicas pela prática de atos contra a administração pública, nacional ou estrangeira, e dá outras providências. Disponível em: <http://www.planalto.gov.br/ccivil_03/_ato2011-2014/2013/lei/112846.htm>

Lei n. 13.019, DE 31/07/2014. Estabelece o regime jurídico das parcerias voluntárias, envolvendo ou não transferências de recursos financeiros, entre a administração pública e as organizações da sociedade civil, em regime de mútua cooperação, para a consecução de finalidades de interesse público; define diretrizes para a política de fomento e de colaboração com organizações da sociedade civil; institui o termo de colaboração e o termo de fomento; e altera as Leis nos 8.429, de 2 de junho de 1992, e 9.790, de 23 de março de 1999. Disponível em: <http://www.planalto.gov.br/ccivil_03/_Ato2011-2014/2014/Lei/L13019.htm>

Lei n. 8.666, de 21 de junho de 1993. Regulamenta o art. 37, inciso XXI, da Constituição Federal, institui normas para licitações e contratos da Administração Pública e dá outras providências. Disponível em:

Lei № 3.071, de 1 de janeiro de 1916. Código Civil dos Estados Unidos do Brasil. Disponível em: < http://www.planalto.gov.br/ccivil_03/leis/13071.htm>

CONSELHO DO COMUNIDADE SOLIDÁRIA-PR. O Conselho da Comunidade Solidária e a construção de novas relações entre Estado e sociedade no Brasil: o Governo e o Terceiro Setor. Documento de referência para a XV Reunião do Conselho, Brasília, Granja do Torto, 30 de junho de 1997a, apud MENDES, Luiz Carlos Abreu. Visitando o "Terceiro Setor" (ou parte dele). Texto para discussão n 647. IPEA, Brasília, maio de 1999. 
COSTA, Wanderley Messias da Fonte. O Brasil e a América do Sul: cenários geopolíticos e os desafios da integração. Confins [Online], 7/2009, posto online em 31/10/2009. Disponível em: http://www.uel.br/cce/geo/didatico/omar/brasil_america_sul.pdf.Capturado em25/01/2015.

FERRAREZI, Elisabete Roseli. A reforma do marco legal do Terceiro Setor no Brasil: a criação da lei das OSCIP (Lei 9.790/99). Tese apresentada no Departamento de Sociologia da Universidade de Brasília, Brasília, mar/2007.

FONTES FILHO, Joaquim Rubens. O que podemos aprender com a governança das organizações públicas e não empresariais. In: O futuro da Governança Corporativa. Org. FONTES FILHO, Joaquin Rubens e LEAL, Ricardo Pereira Câmara. Saint Paul: São Paulo, 2003.

HELMER, Elena. DEMING, Stuart H. Non-Governmental Organizations: Anticorruption Compliance Challenges and Risks. The International Lawyer. Vol. 45, No. 2 (SUMMER2011)

INDEPENDENT SECTOR. Principles for Good Governance and Ethical Practice A Guide for Charities and Foundations (2005). Disponível em: <http://www.hewlett.org/uploads/files/Principles_Guide.pdf $\geq$

INSTITUTO BRASILEIRO DE GOVERNANÇA CORPORATIVA (IBGC). Código das melhores práticas de governança corporativa. 4.ed. Instituto Brasileiro de Governança Corporativa. São Paulo: IBGC, 2009. Disponível em: <http://www.ibgc.org.br/inter.php?id=18180\&email>

LOPEZ, Feliz. BARONE. Leonardo. As Entidades Sem Fins Lucrativos e as Políticas Públicas Federais: tipologia e análise de convênios e organizações. (2003-2011). Texto para discussão nº 1896. IPEA, Brasilia, nov. 2013

MENDONÇA, Luciana Rocha de. MACHADO FILHO, Cláudio Antonio Pinheiro. Governança nas organizações do terceiro setor: considerações teóricas. Revista de Administração da USP, São Paulo, v.39, n.4, p.302-308, out./nov./dez. 2004.

MOREIRA NETO, Diogo de Figueiredo. FREITAS, Rafael Véras de, A juridicidade da Lei Anticorrupção Reflexões e interpretações prospectivas. Revista Forum Administrativo. fev.2014.

OLAK, P. A.; NASCIMENTO, D. T. do. Contabilidade para entidades sem fins lucrativos (terceiro setor). 2.ed. São Paulo: Atlas, 2008.

PIRES, Antônio Cecílio Moreira. A desconsideração da personalidade jurídica nas contratações públicas. São Paulo: Atlas, 2014.

ROSSETTI, José Paschoal. ANDRADE, Adriana. Governança corporativa: fundamentos, desenvolvimento e tendências. 5a ed. atual. e ampl. São Paulo: Atlas, 2011.

Programa das Nações Unidas para o Desenvolvimento - PNUD Brasil. Disponível em: $<$ http://www.pnud.org.br/Noticia.aspx?id=901>

TSAI, P. Y; YAMAMOTO, M. M. Governança corporativa: Análise comparativa entre o setor privado e o terceiro setor. Anais Congresso Contabilidade e Controladoria - USP, São Paulo,Outubro/2005 
UNITED NATIONS. Handbook on Non-Profit Institutions in the System of National Accounts. United Nations, New York, 2003

VARGAS, Sandra Ibañez. Dissertação de Mestrado. Faculdade de economia, administração e contabilidade/USP, São Paulo, 2008.

Trabalhoenviadoem22deabrilde2016.

Aceito em 03 de maio de 2016. 